\title{
Influence of particle size on the pathology and efficacy of vaccination in a murine model of inhalational anthrax
}

\begin{abstract}
Correspondence
Richard Thomas

rjthomas@dstl.gov.uk
\end{abstract}

Received 7 July 2010

Accepted 19 August 2010

\author{
Richard Thomas, ${ }^{1}$ Carwyn Davies, ${ }^{1}$ Alejandro Nunez, ${ }^{2}$ Stephen Hibbs, ${ }^{1}$ \\ Helen Flick-Smith, ${ }^{1}$ Lin Eastaugh, ${ }^{1}$ Sophie Smither, ${ }^{1}$ Amanda Gates, ${ }^{1}$ \\ Petra Oyston, ${ }^{1}$ Timothy Atkins ${ }^{1}$ and Steve Eley ${ }^{1}$ \\ ${ }^{1}$ Defence, Science \& Technology Laboratory (Dstl), Porton Down, Salisbury SP4 OJO, UK \\ ${ }^{2}$ Veterinary Laboratory Agency, Weybridge, New Haw, Addlestone KT15 3NB, UK
}

\begin{abstract}
Deposition of Bacillus anthracis endospores within either the lungs or nasal passages of $A / J$ mice after aerosol exposure was influenced by different particle sized aerosols and resulted in different infection kinetics. The infection resulting from the inhalation of endospores within a $12 \mu \mathrm{m}$ particle aerosol was prolonged compared to that from a $1 \mu \mathrm{m}$ particle aerosol with a mean time-to-death of $161 \pm 16.1 \mathrm{~h}$ and $101.6 \pm 10.4 \mathrm{~h}$, respectively. Inhalation of endospores within $1 \mu \mathrm{m}$ or $12 \mu \mathrm{m}$ particle aerosols resulted in a median lethal dose of 2432 and 7656 c.f.u., respectively. Initial involvement of the upper respiratory tract lymph nodes was observed in $75-83 \%$ of mice exposed to either the $1 \mu \mathrm{m}$ or $12 \mu \mathrm{m}$ particle inhalational infections. Lung deposition was significantly greater after inhalation of the $1 \mu \mathrm{m}$ particle aerosol with pronounced involvement of the mediastinal lymph node. Gastrointestinal involvement was observed only in mice exposed to $12 \mu \mathrm{m}$ particle aerosols where bacteriological and histopathological analysis indicated primary gastritis (17\%), activation of the Peyer's patches ( $72 \%)$ and colonization and necrosis of the mesenteric lymph nodes (67\%). Terminal disease was characterized by bacteraemia in both inhalational infections with preferential dissemination to spleen, liver, kidneys and thymus. Immunization with $1 \mu \mathrm{g}$ recombinant protective antigen vaccine was equally efficacious against $B$. anthracis infections arising from the inhalation of 1 and $12 \mu \mathrm{m}$ particle aerosols, providing 73$80 \%$ survival under a suboptimum immunization schedule.
\end{abstract}

\section{INTRODUCTION}

Anthrax is caused by the Gram-positive sporulating bacterium Bacillus anthracis. The disease is clinically presented in three main forms: cutaneous, inhalational and gastrointestinal (Tutrone et al., 2002; Holty et al., 2006a, b; Beatty et al., 2003; Goossens, 2009). The bioterrorist attacks in the US using B. anthracis endospores contained within letters has heightened concern about inhalational anthrax due to the high mortality and difficulty in treatment (Jernigan et al., 2002; Holty et al., 2006a, b). The size of aerosolized particles influences disease progression by affecting the site of microbial deposition in the respiratory tract. Small particles are inhaled into the alveolar region producing an acute infection whilst larger particles lodge in the upper airways producing a prolonged infection that initiates in the upper airway mucosa and lymphatic tissues.

Abbreviations: FFAG, flow-focusing aerosol generator; LRT, lower respiratory tract; MLD, median lethal dose; MTD, mean time-to-death; NALT, nasal-associated lymphoid tissue; rPA, recombinant protective antigen; SLN, submandibular lymph node; URT, upper respiratory tract.
This has been demonstrated for a number of microorganisms in animal models, including Yersinia pestis (Druett et al., 1956a; Thomas et al., 2009), Brucella suis (Druett et al., 1956b), Francisella tularensis (Day \& Berendt, 1972) and Bacillus anthracis (Druett et al., 1953). Indeed, differential regional deposition of ricin toxin has been demonstrated with similar effects (Roy et al., 2003).

Pathological progression of inhalational anthrax results from endospore deposition within the lung alveoli. Alveolar macrophages and lung dendritic cells traffic the endospores to draining lymph nodes where germination occurs. Vegetative cells are then disseminated to visceral organs including the liver and spleen (Passalacqua \& Bergman, 2006; Loving et al., 2007). Interestingly, a study using a bioluminescent $B$. anthracis strain revealed that in small particle aerosol and intranasal challenges, infection initiated in the nasal-associated lymphoid tissue (NALT) before progression to the draining submandibular lymph node (SLN). Surprisingly, histological analysis revealed little involvement of the lungs or mediastinal lymph nodes despite substantial regional deposition (Glomski et al., 
2007b, 2008). Ultimately, terminal disease ensues as a result of bacteraemia and toxaemia (Passalacqua \& Bergman, 2006; Frankel et al., 2009).

This study aimed to investigate the effect of differential deposition of 1 and $12 \mu \mathrm{m}$ particle aerosols containing $B$. anthracis STI endospores with respect to the progression of infection in the $\mathrm{A} / \mathrm{J}$ murine model and represents the first study, to our knowledge, to investigate particle sizedependent effects on therapeutic intervention.

\section{METHODS}

Animal care. Female A/J mice (Harlan Laboratories) were housed with access to food and water ad libitum at Advisory Committee on Dangerous Pathogens biological safety level (BSL)-3. Procedures were performed in accordance with the Scientific Procedures (Animals) Act 1986 and the Codes of Practice for the Housing and Care of Animals Used in Scientific Procedures 1989.

Preparation of B. anthracis STI endospores for aerosol challenge. $B$. anthracis STI $\left(\mathrm{pXO}^{+}, \mathrm{pXO}^{-}\right)$was obtained from the Defence Science and Technology Laboratory culture collection (Dstl Porton Down, Salisbury, Wiltshire, UK). Enumeration of vegetative cells and endospores was routinely performed on Columbia Blood agar plates at $37{ }^{\circ} \mathrm{C}$ for $24 \mathrm{~h}$ producing large $(6-8 \mathrm{~mm})$, irregular, greyish-white dull colonies with typical 'ground or frostedglass' appearance. Endospores were prepared for aerosol exposures by creating a confluent lawn on isolation medium. The lawn was incubated for 7 days and percentage sporulation was enumerated periodically by plating samples before and after heat-shock at $70{ }^{\circ} \mathrm{C}$ for $1 \mathrm{~h}$. Once the lawn was deemed to comprise $100 \%$ endospores, sterile distilled water was used to harvest the endospores. The endospores were cleaned by washing 10 times by repeated centrifugation (10000 $\mathrm{g}$ for $10 \mathrm{~min}$ ) and resuspended in sterile distilled water. The endospores were heat-shocked at $70{ }^{\circ} \mathrm{C}$ for $1 \mathrm{~h}$ and adjusted to a final concentration of $7.15 \times 10^{9}$ c.f.u. $\mathrm{ml}^{-1}$. A final concentration of $0.01 \%(\mathrm{v} / \mathrm{v})$ Tween- 80 was added. The required dilutions were prepared in sterile distilled water in $10 \mathrm{ml}$ volumes immediately prior to challenge. Isolation medium was prepared by addition of nutrient broth No.2 (Oxoid; $6.0 \mathrm{~g} \mathrm{l}^{-1}$ ), technical agar No.3 (Oxoid; $12.0 \mathrm{~g} \mathrm{l}^{-1}$ ), $\mathrm{MnSO}_{4} \cdot \mathrm{H}_{2} \mathrm{O}$ (Sigma-Aldrich; $0.3 \mathrm{~g} \mathrm{l}^{-1}$ ) and $\mathrm{KH}_{2} \mathrm{PO}_{4}$ (Sigma-Aldrich; $0.25 \mathrm{~g} \mathrm{l}^{-1}$ ) to $1000 \mathrm{ml}$ distilled water. The $\mathrm{pH}$ was adjusted to $\mathrm{pH} 6.7$ prior to sterilization at $121{ }^{\circ} \mathrm{C}$ for $15 \mathrm{~min}$.

Aerosol exposures. Groups of 10 mice were nose-only exposed for a period of $10 \mathrm{~min}$ to aerosols generated by the Collison nebulizer or flow-focusing aerosol generator (FFAG) according to the methodology previously described (Thomas et al., 2008, 2009). Aerosol samples from the challenges involving the Collison nebulizer were collected for $1 \mathrm{~min}$ into an all-glass impinger (AGI-30; Ace Glass) containing $10 \mathrm{ml}$ PBS at a flow rate of $121 \mathrm{~min}^{-1}$. The impinger samples were serially diluted and plated onto Columbia blood agar for enumeration. All exposures were performed within a rigid unpolymerized polyvinylchloride half-suit isolator at BSL-3. The mass median aerosol diameters of the particles were $1-3 \mu \mathrm{m}$ and $12 \mu \mathrm{m}$, respectively, for the Collison nebulizer and the FFAG. The mean calculated inhaled dose for small particles was determined using the impinger data and Guyton's formula (Guyton, 1947). The actual mean inhaled dose for small or large particles was derived from physical washing or dissection and homogenization of the nasal passages, trachea and lungs as described below.

Deposition and infection kinetics. At specific time points, five mice were culled by intraperitoneal administration of $0.5 \mathrm{ml}$ sodium pentobarbital $(0 \mathrm{~h})$ or halothane intoxication (remaining time points) and lungs, mediastinal lymph node, Peyer's patches, gastrointestinal lymph nodes (mesenteric, jejunal, colonic), trachea, oesophagus, stomach, intestine, liver and kidneys were aseptically collected. Blood was collected by cardiac puncture after halothane anaesthetization into heparin-coated plasma tubes (BD Biosciences). Endospores deposited in the nasal passages (nasal washings) were collected by inserting a catheter (outer and inner diameter 1.02 and $0.58 \mathrm{~mm}$, respectively; Harvard Apparatus) into a tracheal incision and flushing with $1 \mathrm{ml}$ PBS containing final concentrations of $1 \mathrm{mM}$ $\mathrm{NaOH}$ and $0.1 \%(\mathrm{v} / \mathrm{v})$ Triton $\mathrm{X}-100$. The tissue samples were homogenized in PBS (Gibco, Invitrogen). Bacteria or endospores in all samples were enumerated by serial dilution and plating of $100 \mu \mathrm{l}$ aliquots in triplicate onto Columbia blood agar plates.

Determination of median lethal dose (MLD). Groups of 10 mice were exposed nose-only for $10 \mathrm{~min}$ to aerosolized B. anthracis STI endospores at five different 10 -fold dilutions generated by either the Collison nebulizer or the FFAG decreasing from the 'neat' suspension of $10^{9}$ c.f.u. $\mathrm{ml}^{-1}$. Mice were monitored for 21 days post-exposure for signs of infection. Mice showing signs of infection were culled by cervical dislocation at defined humane end points. The MLD was calculated by the $50 \%$ end point method (Reed \& Muench, 1938), based on the number of bacteria retained in the lungs or nasal passages of animals that received the neat suspension. Immediately after exposure, five animals per dose were sacrificed for necroscopy with removal of the lungs, trachea, oesophagus and stomach. The nasal passages were washed as previously described. The number of bacteria retained in the lungs or nasal passages was demonstrated to decrease by one logarithm with each logarithmic dilution of the spray suspension used in the dilution series.

Histopathology. The mice were dissected to expose the abdominal and thoracic cavities. The lungs were inflated by instillation of $1.5 \mathrm{ml}$ $10 \%(\mathrm{v} / \mathrm{v})$ neutral-buffered formalin (NBF). The whole mouse was fixed in $10 \%(\mathrm{v} / \mathrm{v}) \mathrm{NBF}$ for 6 days with replacement with a fresh aliquot after 3 days. After a further 3 days fixation, samples from a range of tissues including lungs (apical, medium and caudal lobes), lymph nodes (mediastinal, submandibular/cervical, inguinal and mesenteric nodes), nasal cavity including NALT and turbinates, pharynx, trachea, thymus, thyroid, eyes, brain (including olfactory bulb), oesophagus, stomach, intestine, jejunum containing Peyer's patches, spleen, liver, kidneys and sternal bone marrow were blocked and embedded in paraffin wax. Serial $4 \mu \mathrm{m}$ thick sections were cut using a Leica RM2025 microtome (Leica Microsystems) and dried onto a slide at $37{ }^{\circ} \mathrm{C}$ overnight. Sections were stained with haematoxylin and eosin or Gram Twort before examination using a Leica DM4000B microscope. Images were taken using a Leica DFC480 digital camera (Leica Microsystems). Animals were scored on the basis of the number displaying the particular type of pathology and the severity of pathology according to the system previously described (Thomas et al., 2009).

Immunization and challenge of mice. $B$. anthracis recombinant protective antigen ( $\mathrm{rPA}$ ) was prepared from Escherichia coli $\mathrm{K}-12$ as described by Williamson et al. (2005). Mice $(n=15)$ were injected intramuscularly with a single dose of $1 \mu \mathrm{g}$ B. anthracis $\mathrm{rPA}$ adsorbed to $0.26 \%(\mathrm{v} / \mathrm{v})$ Alhydrogel (Brenntag Biosector). Mice $(n=15)$ injected with PBS and $0.26 \%(\mathrm{v} / \mathrm{v})$ Alhydrogel served as controls. Twenty-one days later, mice were exposed to B. anthracis endospores contained within small- or large-particle aerosols in groups of 15 .

Measurement of pre-challenge serum antibodies. Microtitre plates (Immulon 2; Dynex Technologies) were coated overnight at $4{ }^{\circ} \mathrm{C}$ with $5 \mu \mathrm{g} \mathrm{ml}^{-1} \mathrm{rPA}$ antigen in PBS, except for two control rows per plate that were coated with $5 \mu \mathrm{g}$ goat anti-mouse antibody binding fragment (FAb; Sigma-Aldrich) $\mathrm{ml}^{-1}$. Plates were washed 
( $\times 3$ ) with PBS containing $1 \%(\mathrm{v} / \mathrm{v})$ Tween $20(\mathrm{PBST})$, then blocked with $5 \%(\mathrm{w} / \mathrm{v})$ skimmed milk powder in PBS for $2 \mathrm{~h}$ at $37{ }^{\circ} \mathrm{C}$. Individual serum samples, double-diluted in $1 \%(\mathrm{w} / \mathrm{v})$ skimmed milk powder in PBS, were added to the rPA-coated wells and assayed in duplicate alongside a murine IgG standard (Sigma-Aldrich) added to the anti-FAb-coated wells and incubated overnight at $4{ }^{\circ} \mathrm{C}$. After washing $(\times 3)$ with PBST, horseradish peroxidase-conjugated goat anti-mouse IgG (Sigma-Aldrich) was added to all wells and incubated for $1 \mathrm{~h}$ at $37^{\circ} \mathrm{C}$. After a final wash with PBST, bound antibody was detected by the addition of ABTS substrate (Sigma-Aldrich) containing $0.04 \%(\mathrm{v} / \mathrm{v}) \mathrm{H}_{2} \mathrm{O}_{2}$. Plates were incubated for $20 \mathrm{~min}$ at room temperature and read on a Multiskan Ascent photometer (414 nm; Thermo Fisher Scientific). Titres were calculated using ELISA for Windows (CDC, USA). The limit of detection was $6 \mathrm{ng} \mathrm{rPA} \mathrm{ml}^{-1}$.

Statistical analysis. Data are expressed as the standard error (SE) around the mean. Tissues containing bacterial loads below the limit of detection ( $<10$ c.f.u. per organ) were designated culture-negative. A two-sample $t$-test was used to test the significant differences in the deposition data. The significant differences in the vaccine studies were analysed by ANOVA followed by Tukey's Honestly Significant Difference post-test. $P$-values of $<0.05$ were considered significantly different.

\section{RESULTS AND DISCUSSION}

\section{Particle size affects deposition site}

Particle size-related deposition of $B$. anthracis endospores has previously been shown to increase MLD and mean time-to-death (MTD) in the guinea pig model (Druett et al., 1953). A murine model has not been reported for the investigation of particle size-dependent effects of inhalational anthrax and the subsequent assessment of therapeutics. Since the A/J murine model has been reported for the evaluation of therapeutics against inhalational anthrax using B. anthracis STI delivered by small-particle aerosol (Flick-Smith et al., 2005), we utilized A/J mice to investigate inhalational anthrax caused by deposition of
B. anthracis within the upper respiratory tract (URT) by using larger particles.

The Collison nebulizer and FFAG were used to expose A/J mice to 1 and $12 \mu \mathrm{m}$ particle aerosols containing $B$. anthracis STI endospores from an initial starting concentration of $1.5 \pm 0.16 \times 10^{9}$ c.f.u. $\mathrm{ml}^{-1}$. The site of deposition was determined within $30 \mathrm{~min}$ of exposure (Fig. 1). Differential deposition between the lower respiratory tract (LRT) and URT was observed for the 1 and $12 \mu \mathrm{m}$ particle aerosols. The $1 \mu \mathrm{m}$ particle aerosol deposited primarily in the lung tissue $(19.7 \%)$ compared to the nasal passages $(0.2 \% ; P=0.0002)$. In contrast, the $12 \mu \mathrm{m}$ particle aerosol deposited primarily in the nasal passages $(40.9 \%)$ compared to the lungs $(1.7 \% ; P=0.0001)$. Comparably low numbers of endospores were present in the trachea and oesophagus while similarly higher levels were enumerated in the stomach for mice exposed to small- and large-particle aerosols. Large numbers of endospores were cleared to the stomach, equating to $77.3 \%$ and $56.67 \%$ of the total number deposited in the mice for small- and large-particle aerosols, respectively.

The deposition profiles obtained for the aerosols generated by the Collison nebulizer and FFAG are comparable to previously obtained profiles for Escherichia coli and Yersinia pestis (Thomas et al., 2008, 2009). The profile obtained in this study had much greater levels of $B$. anthracis in the gastrointestinal tract compared to $Y$. pestis. This is probably due to the higher resistance of $B$. anthracis endospores to the acidity of the stomach. Endospores, including those of $B$. anthracis, are known to be highly resistant to a range of stressful conditions including low pH (Nicholson et al., 2002; Setlow, 2006). In contrast, Y. pestis is much less tolerant and requires a large dose to initiate infection via the oral route in the murine model (Butler et al., 1982).

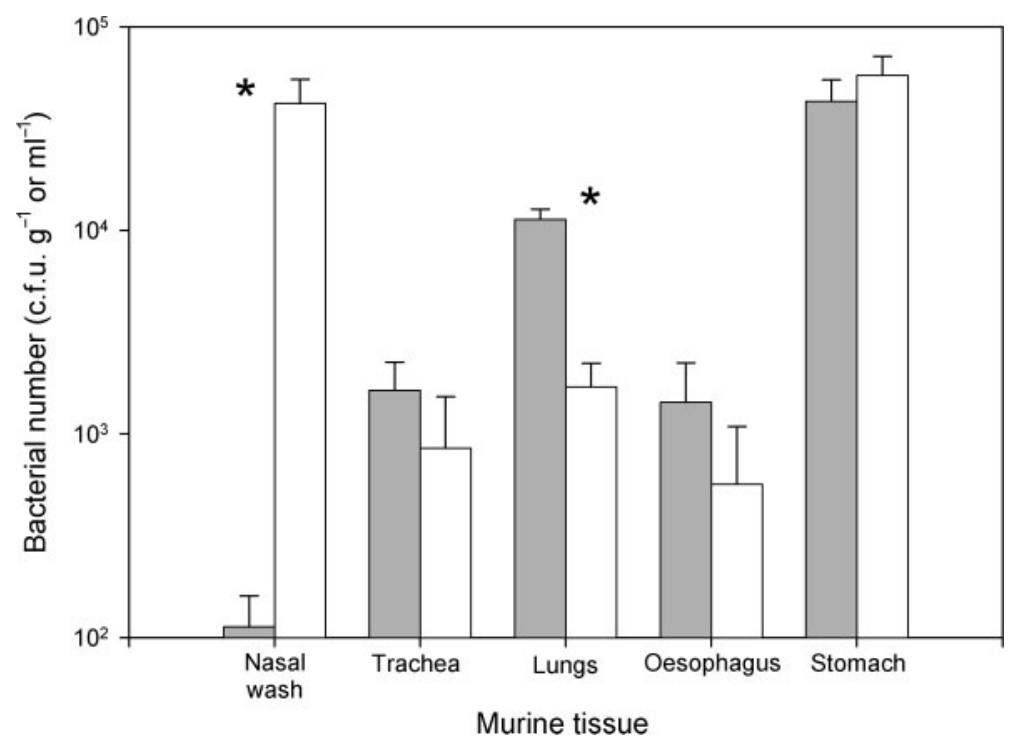

Fig. 1. Initial deposition of $B$. anthracis STI endospores after exposure to 1 and $12 \mu \mathrm{m}$ particle aerosols (shaded and open bars, respectively); values represent 30 min postchallenge. Error bars represent the standard errors $(n=10)$. Asterisks represent significant difference between particle sizes. 


\section{Inhalation of greater numbers of endospores within $12 \mu \mathrm{m}$ particles is required to induce infection}

The number of $B$. anthracis STI endospores necessary to induce lethal infection in the $\mathrm{A} / \mathrm{J}$ murine model was determined as a function of particle size. A suspension of endospores at a concentration of $1.35 \pm 0.22 \times 10^{9}$ c.f.u. $\mathrm{ml}^{-1}$ was aerosolized using either the Collison nebulizer or FFAG to generate 1 and $12 \mu \mathrm{m}$ particle aerosols, respectively. A calculated retained lung dose of $2.5 \times 10^{4}$ c.f.u. for the $1 \mu \mathrm{m}$ particle aerosol was obtained using impinger samples. This equated well to the actual retained dose of $1.13 \pm 0.14 \times 10^{4}$ c.f.u. $\mathrm{g}^{-1}$ from the lungs and $1.13 \pm 0.47 \times 10^{2}$ c.f.u. $\mathrm{ml}^{-1}$ in the nasal passages after necroscopy. In contrast, when a $12 \mu \mathrm{m}$ particle aerosol was generated, quantities of $3.7 \pm$ $0.52 \times 10^{2}$ c.f.u. $\mathrm{g}^{-1}$ were recovered from the lungs and $4.2 \pm 1.31 \times 10^{4}$ c.f.u. $\mathrm{ml}^{-1}$ from the nasal passages upon necroscopy. Tenfold serial dilutions of the initial suspension used for challenge resulted in approximate 10 -fold reductions in the numbers of endospores deposited in the lungs or nasal passages (data not shown).

Mice that inhaled a retained dose of $10^{4}$ c.f.u. within a $1 \mu \mathrm{m}$ particle aerosol displayed $78 \%$ mortality with a MTD of $101.6 \pm 10.4 \mathrm{~h}$. Inhalational challenge with 10 - and 100fold lower doses resulted in reduced mortality of $33.3 \%$ and $11.1 \%$, respectively. Less concentrated challenge doses resulted in no mortality over the course of experimentation. Deposition of $10^{4}$ c.f.u. within the nasal passages as a consequence of inhalation of $12 \mu \mathrm{m}$ particle aerosols resulted in $56 \%$ mortality with a MTD of $161 \pm 16.1 \mathrm{~h}$. Challenge with 10- and 100-fold lower doses resulted in reduced mortality of $44.4 \%$ and $33.3 \%$, respectively, whilst all animals survived challenge with lower doses. Irrespective of whether the mice were challenged with 1 or $12 \mu \mathrm{m}$ survivors cleared the infection as evidenced from bacteriological analysis of lung and spleen tissues.

The MLD calculated for the unencapsulated B. anthracis STI strain was 2432 and 7656 endospores for the 1 and $12 \mu \mathrm{m}$ particle aerosols, respectively, equating to a 3.15-fold increase in the numbers of endospores required to produce infection with the larger particles. The MLD obtained for $1 \mu \mathrm{m}$ particles is similar to that obtained for the fully virulent B. anthracis Ames strain in the A/J model of 1908 endospores with a 95\% CI range of 948-3687 endospores (Heine et al., 2007) but lower than that obtained for the unencapsulated B. anthracis Sterne 7702 of $2 \times 10^{5}$ endospores (Loving et al., 2007). In contrast with the results of this study, Drysdale et al. (2005) described the attenuation of $B$. anthracis mutants lacking the capsule biosynthetic and regulatory genes. The $\mathrm{MLDs}$ in the $\mathrm{BALB} / \mathrm{c}$ mice were greater than $5 \times 10^{7}$ c.f.u. for $B$. anthracis strains lacking the capsule synthetic genes (capBACD) or the capsule regulatory genes $(a c p A B)$. One possibility for the observed differences may be the influence of immunodeficiency in the two strains of inbred mice used in these studies. $\mathrm{BALB} / \mathrm{c}$ mice possess a fully functional immune system, whilst $\mathrm{A} / \mathrm{J}$ mice have a mutation in the $H c$ gene causing a deficiency in C5 complement (Welkos et al., 1986). A/J mice also have a defect in the Naip5 protein, a NOD-like receptor that activates caspase- 1 to cleave proIL- $1 \beta$ to IL- $1 \beta$. Such activity is essential for effective macrophage killing of intracellular pathogens, including B. anthracis (Kang et al., 2008, 2010). A further difference is that the mice in the study of Drysdale et al. (2005) were inoculated intratracheally. This delivers the challenge dose to the lungs, bypassing any alternative routes of infection that may be utilized by pathogens deposited into the respiratory tract by inhalation (e.g. URT lymphoid tissues or gastrointestinal tract). These alternative portals of entry for infection may not be as dependent upon capsule expression as infection via the lungs.

Utilizing all the animal data from challenge doses that deposited $10^{4}$ c.f.u. within the lungs or nasal passages and proved fatal $(n=89)$, the MTD was determined as $98.7 \pm 7.5 \mathrm{~h}$ and $136.2 \pm 10.6 \mathrm{~h}$ for the 1 and $12 \mu \mathrm{m}$ particle aerosols, respectively, significantly greater for the $12 \mu \mathrm{m}$ particle aerosol $(P=0.005)$. The range was 3-7 days and 3-14 days for the 1 and $12 \mu \mathrm{m}$ particle inhalational infections, respectively. Taken together, these data indicate that compared to the infection generated by the inhalation of $B$. anthracis within $1 \mu \mathrm{m}$ particles, inhalation of greater numbers of endospores is required to generate the more protracted infection via URT deposition. Similar conclusions were drawn from the study of particle size-dependent inhalational studies in B. anthracis using guinea pigs as the animal model where the respiratory lethal dose was $0.23-3.4 \times 10^{5}$ and $0.7-5.7 \times 10^{6}$ c.f.u. for 1 and $12 \mu \mathrm{m}$ particle aerosols, respectively (Druett et al., 1953).

\section{Pathological progression of inhalational anthrax differs with respect to particle size}

The progression of inhalational anthrax was investigated as a function of particle size by bacteriological and histopathological analysis. The differences and similarities between the two inhalational infections are summarized in Table 1, indicating greater involvement of the LRT in the $1 \mu \mathrm{m}$ particle infection, whilst greater involvement of the gastrointestinal tract was observed in the $12 \mu \mathrm{m}$ particle infection. Involvement of the URT was observed irrespective of the size of the particles inhaled. Immediately after aerosol deposition $(0 \mathrm{~h})$, endospores were primarily localized to either the lungs or nasal passages depending on the size of the inhaled particles (Fig. 2). All samples at the $0 \mathrm{~h}$ time point were resistant to heat treatment, indicating the presence of endospores rather than vegetative bacilli. Germination of the endospores predominantly occurred within $24 \mathrm{~h}$, indicated by the predominance of heat-sensitive vegetative cells at this time point. Thereafter, from the $48 \mathrm{~h}$ time point all samples were heat-sensitive, indicating germination of the endospores into vegetative bacilli (data not shown). Lung involvement occurred in both infections but was more pronounced in mice that inhaled endospores within $1 \mu \mathrm{m}$ particle aerosols with 
Table 1. Comparative histopathological and bacteriological progression of inhalational anthrax infections in the major tissues affected

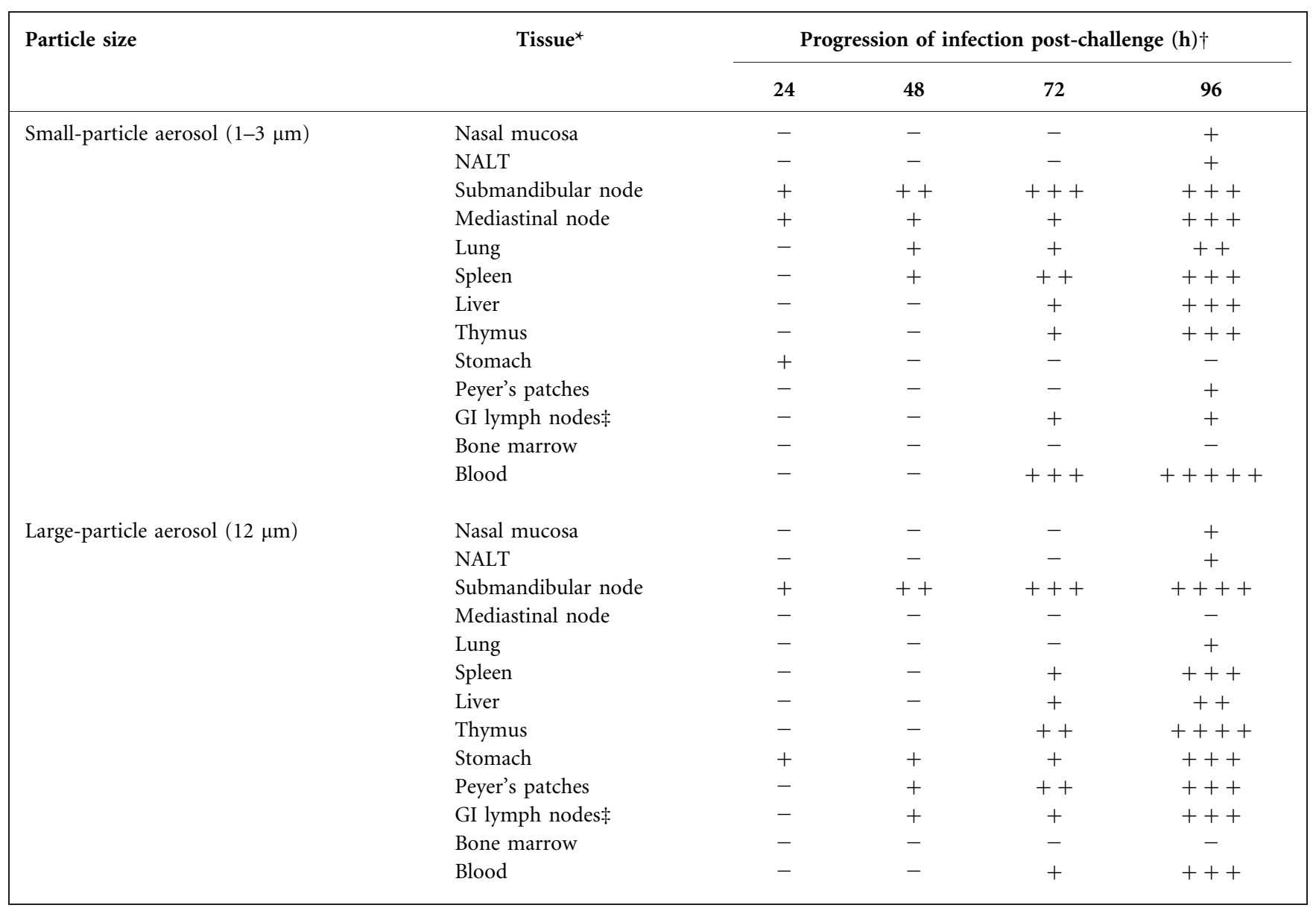

*Intestine, pharynx, oesophagus and kidneys were negative until $96 \mathrm{~h}$ post-infection in both 1 and $12 \mu \mathrm{m}$ inhalational infections correlating with bacteraemia. B. anthracis was observed only in the capillaries of these organs. GI, Gastrointestinal.

$\dagger$ Severity of pathological sequelae is scored subjectively according to the methods: - , none;,+ mild; ++ , moderate; +++ , marked; ++++ , major; +++++ , severe.

‡GI lymph nodes comprise the mesenteric, jejunal and colonic lymph nodes that drain from the Peyer's patches (Van den Broeck et al., 2006).

numbers of vegetative bacteria approaching $10^{7}$ c.f.u. $\mathrm{g}^{-1}$ at $96 \mathrm{~h}$ post-infection. In contrast, approximately $10^{5} \mathrm{c}$.f.u. $\mathrm{g}^{-1}$ bacteria were present at $96 \mathrm{~h}$ post-infection in the lungs of mice that inhaled the $12 \mu \mathrm{m}$ particle aerosol. Histologically, no evidence of germination was observed in the lung parenchyma, and these vegetative cells are likely to be the result of bacteraemia. Colonization of the mediastinal lymph node was significantly greater in the $1 \mu \mathrm{m}$ particle infection (Fig. 2). Mediastinitis has been observed in inhalational anthrax caused by the lung deposition of small particle aerosols in other animal models, including rabbits and non-human primates (Fritz et al., 1995; Lever et al., 2008; Twenhafel et al., 2007; Vasconcelos et al., 2003; Zaucha et al., 1998), and widening of the mediastinum is one of the clinical signs of inhalational anthrax in humans.

Deposition in the nasal passages was significantly higher with the $12 \mu \mathrm{m}$ particle aerosol and bacterial counts remained higher than those associated with the infection caused by the inhalation of $1 \mu \mathrm{m}$ particle aerosols over the $96 \mathrm{~h}$ time-course. Gross facial oedema was observed in $83 \%(15 / 18)$ of mice that inhaled the $12 \mu \mathrm{m}$ particle aerosol. This was previously observed in guinea pigs and monkeys exposed to $B$. anthracis in $12 \mu \mathrm{m}$ particle aerosols indicating a localized infection (Druett et al., 1953). Interestingly, histological involvement of the NALT and degradation of the nasal mucosa was observed only on rare occurrences in both the 1 and $12 \mu \mathrm{m}$ particle inhalational infections (Fig. 3). In $8 \%(1 / 12)$ and $17 \%(3 / 18)$ of mice that inhaled 1 and $12 \mu \mathrm{m}$ particle aerosols, respectively, ulceration and colonization of the nasal mucosa were evident with masses of vegetative $B$. anthracis cells present. Concomitantly, massive structural degradation of NALT was observed with lymphocyte necrosis by large numbers of proliferating bacteria. This represented a primary route of entry into the body for the endospores within these animals. However, this is in contrast to previous reports where NALT involvement was much more commonly 

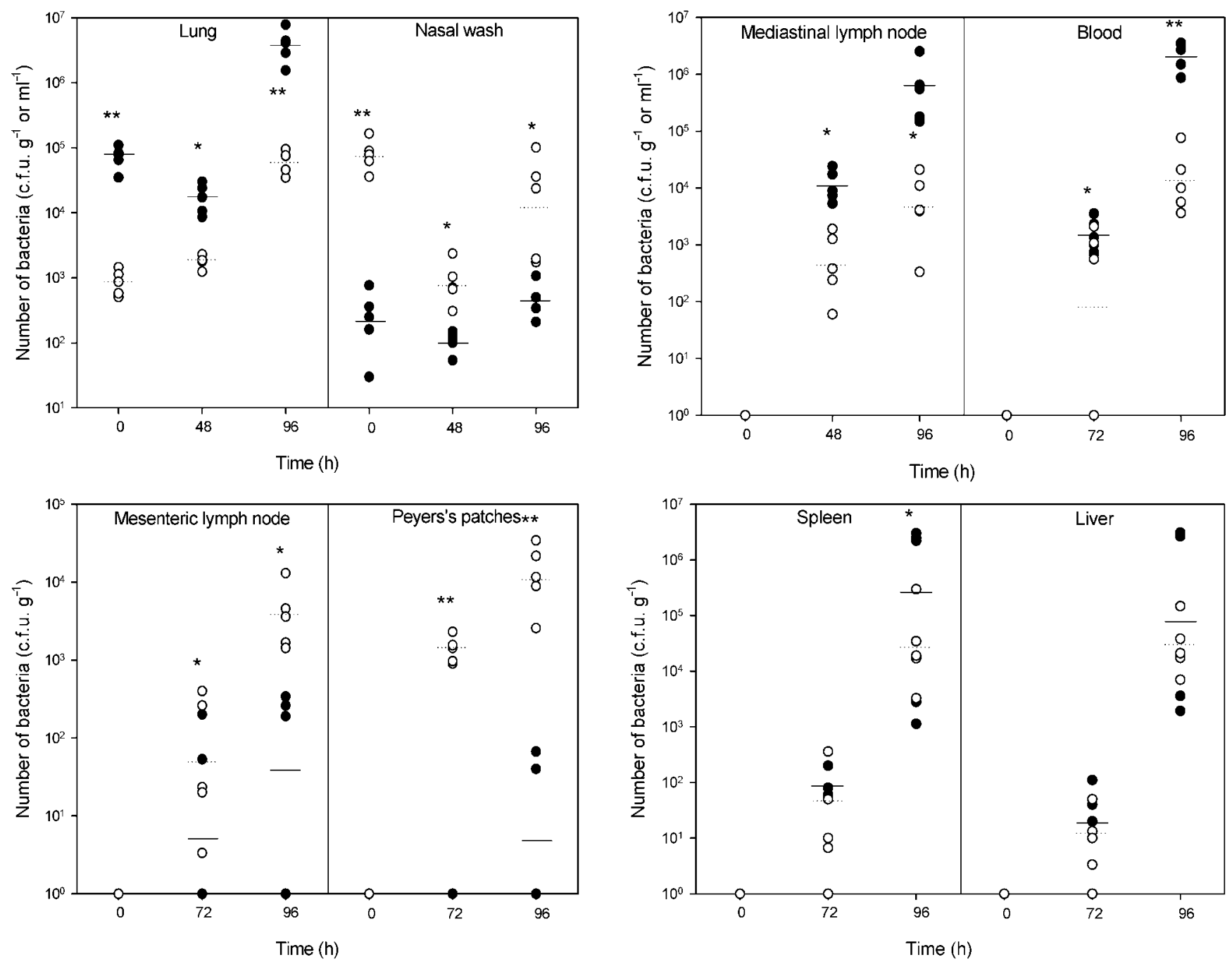

Fig. 2. Bacteriological kinetics within tissues of $A / J$ mice exposed to aerosols of different particle size of $B$. anthracis STI endospores. - Small particle $(1 \mu \mathrm{m})$ infection generated by the Collison nebulizer; $\bigcirc$, large particle $(12 \mu \mathrm{m})$ infection generated by the FFAG. Mean values are indicated by the solid and dotted lines for the small-particle and large-particle infections, respectively $(n=5)$. Significant differences between the tissue loads for the 1 and $12 \mu \mathrm{m}$ particle inhalational infections are indicated by * $(P<0.05)$ and ${ }^{* *}(P<0.01)$, respectively.

observed (Glomski et al., 2007b; Loving et al., 2009). These differences may be linked to the phenotype of the bacterium: Glomski et al. (2007b) used the non-toxigenic, capsulated strain, 9602P, whilst this study used the unencapsulated strain, STI. Using the unencapsulated Sterne strain, Loving et al. (2009) demonstrated infection of NALT and the draining SLNs with dissemination to the visceral organs. Compared to our study using a $1 \mu \mathrm{m}$ particle aerosol that deposited $10^{5}$ endospores in the lungs, Loving et al. (2009) deposited up to 40 times more endospores. Based on the presented deposition data (Fig. 1), this would translate to increased deposition within the nasopharyngeal region. Specialized cells termed $\mathrm{M}$ cells are located in the epithelial layer of mucosal-associated lymphoid tissues such as NALT and Peyer's patches capable of transporting antigens across the epithelial layer. Greater interaction with these cell types is more likely with increased deposition of endospores. Indeed, $\mathrm{M}$ cells located in NALT have been shown to uptake group A streptococci and influenza virions (Fujimura et al., 2004; Park et al., 2003). Furthermore, it has been postulated that endospores are within the correct size range to be taken up by the $\mathrm{M}$ cells of Peyer's patches (Duc et al., 2003a).

Pathological changes in the SLNs were observed in $75 \%$ $(9 / 12)$ and $83 \%(15 / 18)$ of those animals infected for the 1 and $12 \mu \mathrm{m}$ particle inhalational infections, respectively. Supporting these results, colonization of the SLNs was observed in $82 \%$ of rabbits exposed to small-particle aerosols of B. anthracis endospores (Zaucha et al., 1998). At 


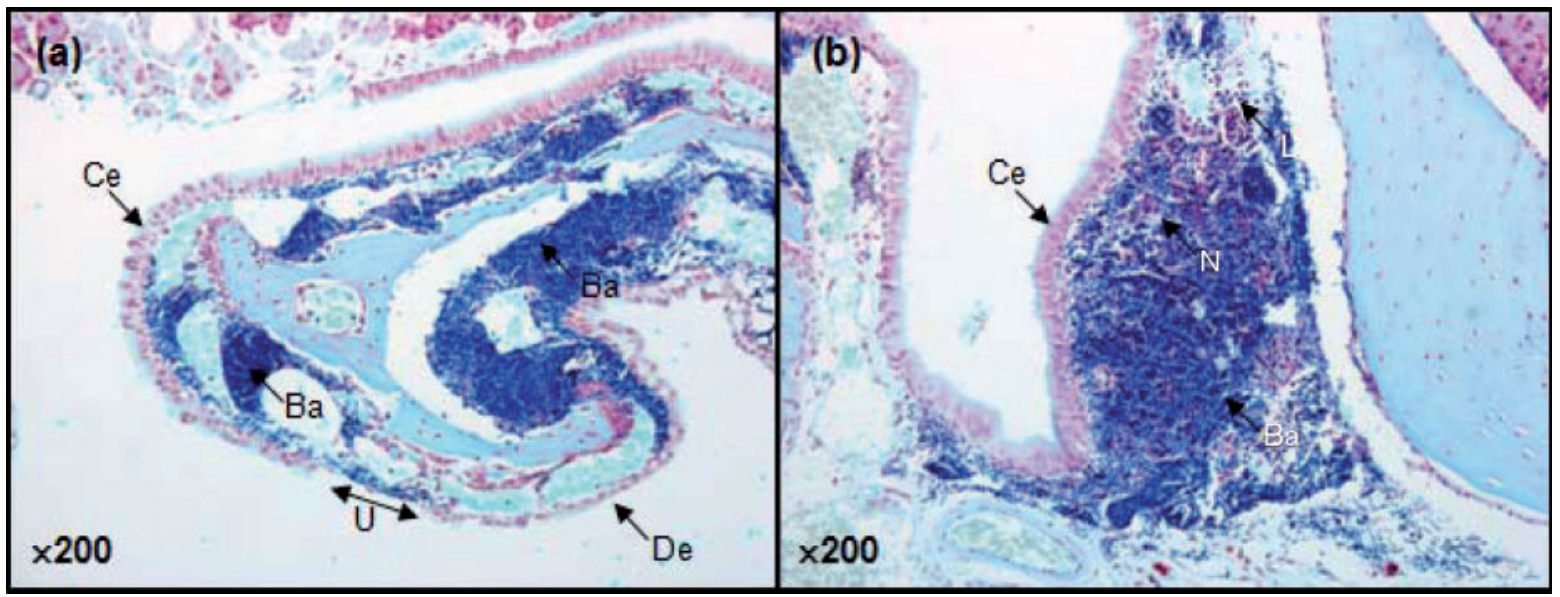

Fig. 3. Pathology of the nasal cavity after the inhalation of $B$. anthracis STI endospores aerosolized in $1 \mu \mathrm{m}$ particles by the Collison nebulizer at $72 \mathrm{~h}$ post-infection. (a) Nasal turbinates and mucosa; (b) NALT. Samples were stained with Gram Twort. The original magnification of each image is indicated. Ba, Bacillus anthracis; Ce, ciliated columnar epithelium; De, deciliated columnar epithelium; L, lymphocytes; $\mathrm{N}$, necrosis; U, ulceration.

$48 \mathrm{~h}$ post-infection, distension of the subcapsular sinuses was observed with the presence of abundant bacteria and focal areas of necrosis and increased numbers of tingible body macrophages (Fig. 4a). By 72-96 h post-infection, structural degradation of the lymph node architecture was observed presenting as a necrotizing lymphadenitis within the subcapsular sinus and cortex. Large numbers of bacteria, severe haemorrhages and hyperaemia were present throughout the SLNs including the medullary sinuses permitting lymphatic dissemination (Fig. 4b). The results presented here with the toxigenic, unencapsulated B. anthracis STI strain support the study of Loving et al. (2009) where dissemination from the draining lymph nodes into visceral organs in the $\mathrm{A} / \mathrm{J}$ mouse model was linked to expression of the lethal toxin subunit (lef). Histopathological analysis indicated that the SLNs are a primary site of infection for both forms of inhalational infection. This raises the question, how do the endospores reach the SLNs? This area requires further research; however, one answer may be via the NALT, and certainly this would appear to be the case in those animals with histopathological involvement of this tissue. Supporting this theory, the URT mucosa of rodents and humans contains antigen-presenting cells (APCs) such as macrophages and dendritic cells that are known to phagocytose bacteria such as Bordetella spp. and transport them to the regional lymph nodes (Gueirard et al., 2003; Jahnsen et al., 2004; Dunne et al., 2009). Furthermore, orally delivered endospores have been recovered from the SLNs (Duc et al., 2003a). In those animals where NALT involvement was not observed histologically, it is possible that APCs within the mucosa could phagocytose the deposited endospores and transport them via the NALT to the SLNs where germination occurs. In addition, spores deposited in the oral cavity, pharynx and URT would also be phagocytosed and drained to those regional lymph nodes.

In both inhalational infections, minimal lung pathology with minimal or no alveolar inflammation was observed, indicating that infection initiated elsewhere despite obvious endospore deposition in the lungs in the case of the $1 \mu \mathrm{m}$ particle aerosols. Furthermore, histological evidence in both 1 and $12 \mu \mathrm{m}$ particle inhalational infections at later stages of infection indicated the presence of bacteria within the alveolar capillaries rather than primary involvement of the alveoli (Fig. 4d). This supports observations from previous studies investigating murine pulmonary anthrax where involvement of the local lung-associated lymph nodes occurred rather than the lung parenchyma (Lyons et al., 2004; Glomski et al., 2007b, 2008) and is consistent with trafficking from the lungs to the local thoracic lymph nodes within alveolar macrophages and interstitial lung dendritic cells (Cleret et al., 2007). Germination has been demonstrated to occur rapidly within the alveolar tissue prior to uptake and transport of the bacteria to the local lymph nodes within professional phagocytes (Sanz et al., 2008).

Gastrointestinal involvement was more pronounced in mice that inhaled B. anthracis endospores within $12 \mu \mathrm{m}$ particles (Table 1). Whether this was the result of primary involvement due to clearance from endospores deposited in the respiratory tract into the gastrointestinal tract or secondary due to bacteraemic or lymphatic dissemination is difficult to ascertain. Primary gastritis with mucosal ulceration was observed in $17 \%$ (3/18) of mice that inhaled B. anthracis STI within $12 \mu \mathrm{m}$ particles. This presentation was not observed in mice that inhaled $1 \mu \mathrm{m}$ particles. At $96 \mathrm{~h}$ post-infection, large numbers of vegetative bacteria 


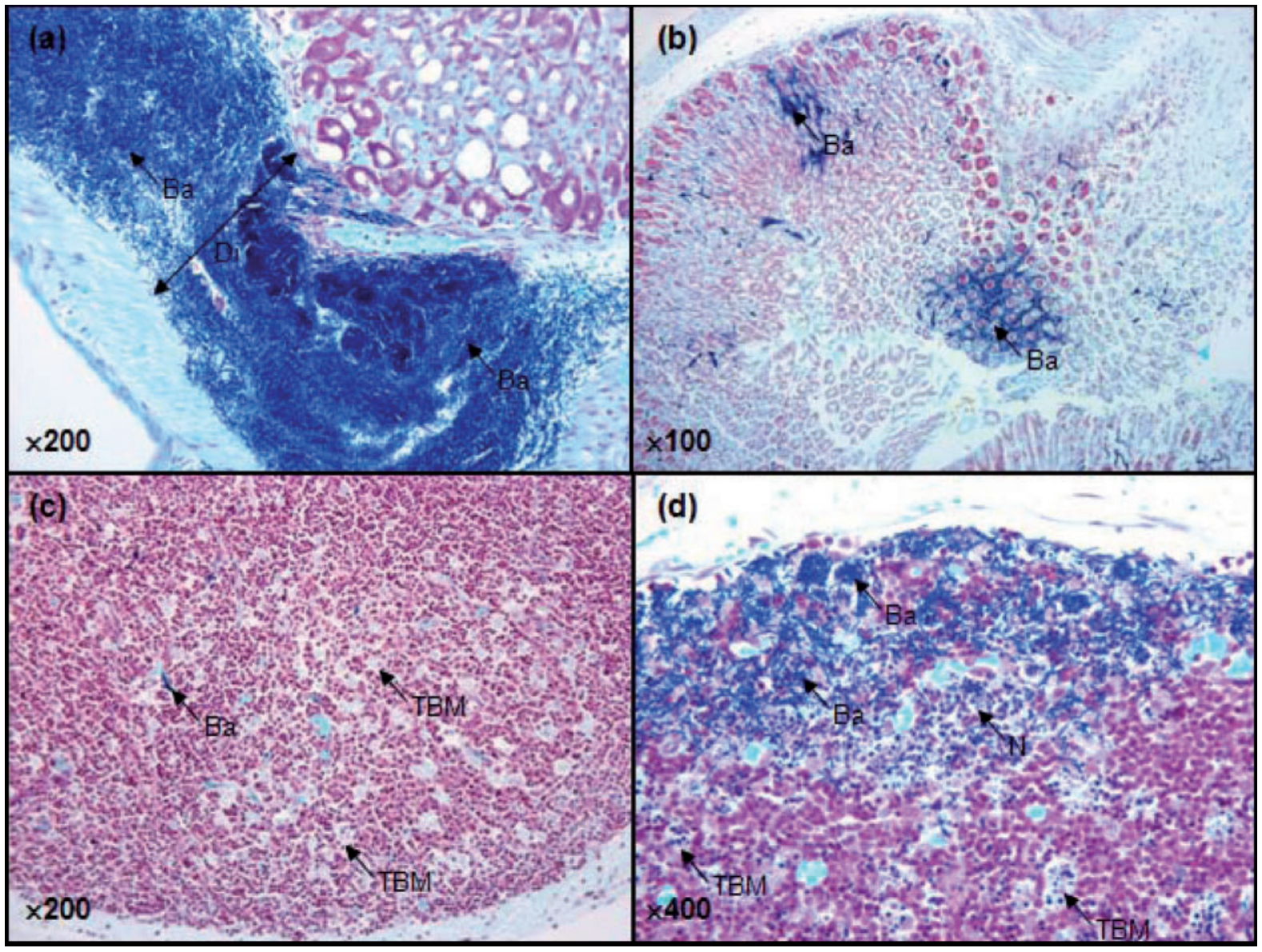

Fig. 4. Pathology of the gastrointestinal tract after inhalation of $B$. anthracis STI endospores aerosolized in $12 \mu \mathrm{m}$ particles. (a, b) Stomach mucosa at $96 \mathrm{~h}$ post-infection, bacterial colonization of the lamina propria; (c) Peyer's patch at $72 \mathrm{~h}$ post-infection; (d) mesenteric lymph node at $96 \mathrm{~h}$ post-infection. Samples were stained with Gram Twort. The original magnification of each image is indicated. Ba, B. anthracis; $\mathrm{Di}$, distended submucosa; N, necrosis; TBM, tingible body macrophage.

were observed within the distended gastric submucosa with focal necrosis of the mucosal epithelium (Fig. 5a). Intravascular bacteria were observed in the capillaries of the stomach mucosa and there was colonization of the lamina propria (Fig. 5b). Supporting these findings, in cynomolgus monkeys that developed inhalational anthrax, $7 \%$ presented with stomach ulceration and $29 \%$ with mucosal and submucosal haemorrhages (Vasconcelos et al., 2003). Interestingly, despite differences in the size of the particles inhaled, there was no significant difference in the numbers of endospores that reached the oesophagus and stomach (Fig. 1). It is known for Bacillus atrophaeus that $12 \mu \mathrm{m}$ particles contain aggregates of endospores as opposed to the singletons that occur in $1 \mu \mathrm{m}$ particles (Thomas et al., 2008). This may prompt the observed differences in infection kinetics through two potential mechanisms. Firstly, aggregates of endospores may survive better within the transit through the stomach and intestine. This is unlikely given that based on tolerance to the gastrointestinal tract Bacillus subtilis endospores have been evaluated as vaccine delivery systems (Duc et al., 2003a, b). A more likely mechanism could centre on the comparative ability of endospores within singlets or aggregates to germinate. Singlet endospores may germinate within the stomach and small intestine leading to killing of the resultant vegetative cells by the low $\mathrm{pH}$, proteases and bile salts present in these environments. Those present in aggregates may be inhibited from germination due to the higher local concentration of enzymes that regulate germination. Enzymes such as alanine racemase and nucleoside hydrolase are known to occur in the exosporium of $B$. anthracis and proposed to hydrolyse small molecule germinants (Todd et al., 2003; Redmond et al., 2004). Stomach colonization was also observed in $\mathrm{A} / \mathrm{J}$ mice that were exposed to aerosolized endospores of an unencapsulated strain (Glomski et al., 2008). These mice were exposed to $1 \mu \mathrm{m}$ particle aerosols that reached concentrations of $10^{5}$ c.f.u. in the lungs.

Bacteriological analysis indicated that the $12 \mu \mathrm{m}$ particle infection was characterized by greater colonization of the Peyer's patches and gastrointestinal lymph nodes (mesenteric, jejunal and colonic) at 72 and $96 \mathrm{~h}$ post-infection 


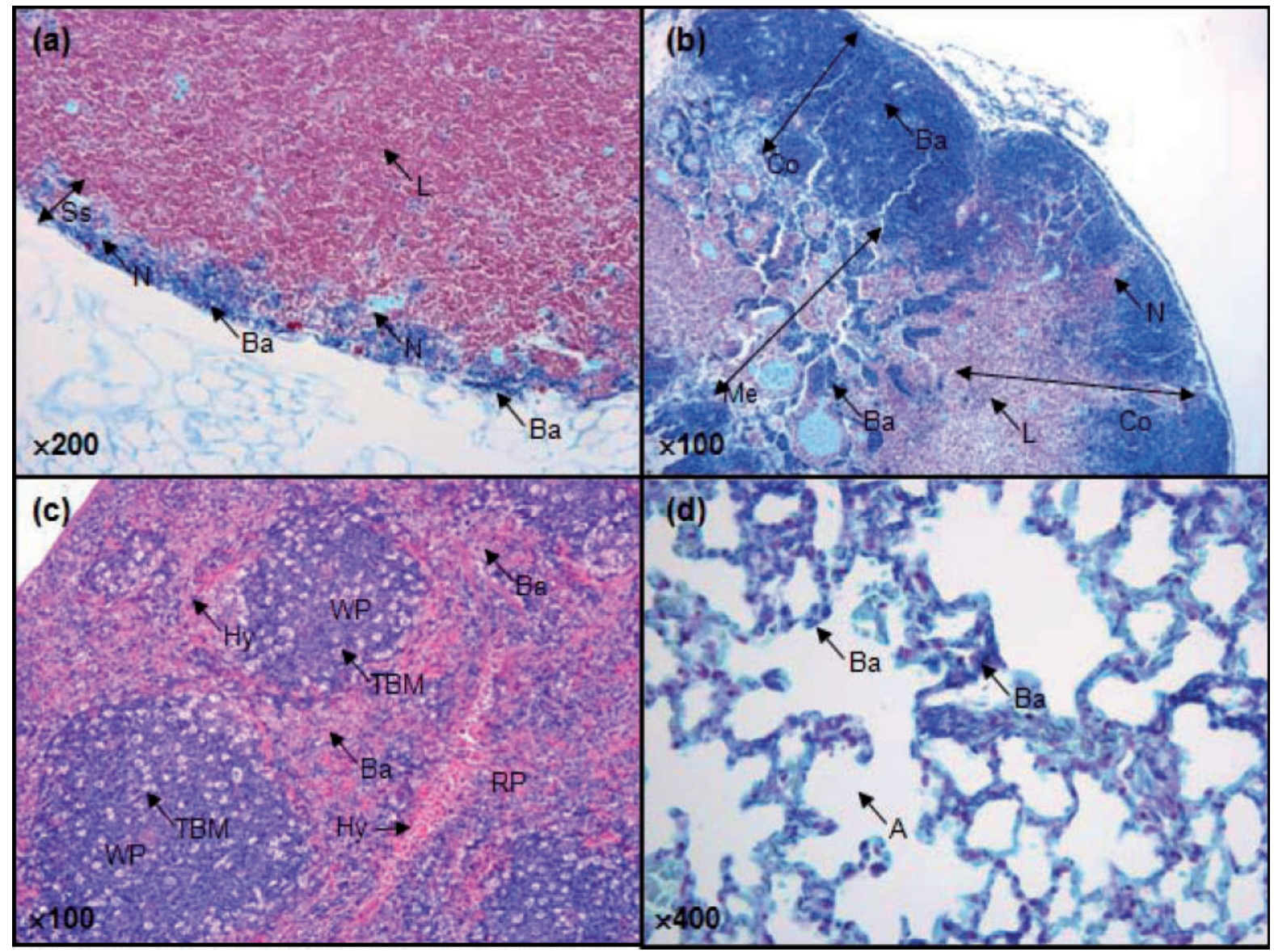

Fig. 5. Tissue histopathology in mice that inhaled $B$. anthracis STI endospores in $12 \mu \mathrm{m}$ particles generated by the FFAG. (a, b) Submandibular lymph node at $48 \mathrm{~h}$ (a) and $96 \mathrm{~h}$ (b) post-infection; (c) spleen at $72 \mathrm{~h}$ post-infection; (d) lung at $72 \mathrm{~h}$ postinfection. Samples were stained with $\operatorname{Gram} \operatorname{Twort}(a, b$ and $d)$ and haemotoxylin and eosin (c). The original magnification of each image is indicated. A, Alveolar space; Ba, B. anthracis; Co, cortex; Hy, hyperaemia; L, lymphocytes; Me, medulla; N, necrosis; $\mathrm{RP}$, red pulp; Ss, subcapsular sinus; TBM, tingible body macrophages; WP, white pulp.

(Fig. 2). Histologically, Peyer's patches showed greater activation in the $12 \mu \mathrm{m}$ particle infection with increased numbers of tingible body macrophages evident in $72 \%$ (13/18) of infected mice (Fig. 5c). In $67 \%$ (12/18) of mice, the mesenteric lymph nodes showed considerable pathology. Numerous bacteria were visible within the distended subcapsular sinuses with necrosis of the underlying cortex and a large increase in tingible body macrophages within the cortex (Fig. 5d). These data support the findings of Glomski et al. (2007a), where Peyer's patches were found to be the primary site of infection after intragastric inoculation of mice with a non-toxigenic strain of $B$. anthracis. The efferent lymphatics within the Peyer's patches drain into the mesenteric lymph nodes. Both lymphoid tissues are involved in oral tolerance and immune responses to gastrointestinal infection (Kwa et al., 2006; Macpherson \& Smith, 2006; Tam et al., 2008) and have been demonstrated to be targeted by orally delivered endospores (Duc et al., 2003a). Gastrointestinal involvement was not noted in the study of Druett et al.
(1953), where guinea pigs and monkeys were exposed to $B$. anthracis within large-particle aerosols. Observations on the difficulties in initiating gastrointestinal anthrax by the oral route and the low numbers of endospores deposited $\left(10^{6}\right)$ in the animals prompted the authors to 'conclude that anthrax developed by way of the respiratory tract and not to any significant extent through the digestive tract'. However, supporting bacteriological and histological evidence was not supplied making direct comparisons with this study difficult. Without doubt, the URT represents the major portal of entry into the body; however, in susceptible individuals the gastrointestinal tract may offer an additional route if a sufficiently large dose is inhaled. Pathology of the Peyer's patches and mesenteric lymph nodes in rabbits after aerosol exposure was observed in 15 and $59 \%$ of cases, respectively (Zaucha et al., 1998). Colonization of the mesenteric lymph nodes has been observed in a number of non-human primate models after exposure to small-particle aerosols (Fritz et al., 1995; Vasconcelos et al., 2003). 
Temporal involvement of the visceral organs (spleen, liver, kidneys, thymus and thyroid) progressed similarly irrespective of the size of the inhaled particles, coinciding with bacteraemia at $48-72 \mathrm{~h}$ post-infection (Table 1). Irrespective of the size of the inhaled particles, in $86 \%$ $(12 / 14)$ of terminal cases, focal areas of necrotic debris and vegetative bacteria were observed in the red and white pulp of the spleen. Diffuse hyperaemia was observed in the red pulp of the spleen with increased numbers of tingible body macrophages within the white pulp (Fig. 4c). In contrast, Drysdale et al. (2005) and Glomski et al. (2007a, 2008) observed that $B$. anthracis strains lacking the ability to express capsule did not disseminate to the spleen. Conversely, the study of Loving et al. (2007) demonstrated dissemination to the spleen using the unencapsulated Sterne 7702 strain. Bacterial concentrations reached $10^{6}$ c.f.u. per organ at the terminal stage of infection, comparable to the concentrations obtained in this study (Fig. 2). At $96 \mathrm{~h}$ post-infection, significantly higher titres of bacteria were observed in the blood of animals that inhaled endospores within $1 \mu \mathrm{m}$ particle aerosols (Fig. 2). During the late stages of the inhalational infections, plugs of bacteria were observed in the kidney glomeruli with interstitial haemorrhages exemplifying the bacteraemic nature of the terminal disease. Generally, liver pathology was localized to the intravascular presence of bacteria during the bacteraemia. However, in $64 \%(9 / 14)$ of terminal cases, focal necrosis of the hepatic parenchyma was observed with bacterial colonization of the sinusoids. At $72-96 \mathrm{~h}$ post-infection, increased numbers of tingible body macrophages were observed in the thymus with intravascular bacteria and in some cases pyknotic and karyorrhectic debris.

Meningoencephalitis was a complication in $50 \%$ of human inhalational anthrax cases occurring in the 1972 outbreak at Sverdlosk, Russia (Meyer, 2003). Indeed, 38-77\% of rhesus macaques, African green and cynomolgus monkeys that inhaled small-particle aerosols of $B$. anthracis presented with suppurative or haemorrhagic meningitis (Fritz et al., 1995; Twenhafel et al., 2007; Vasconcelos et al., 2003). However, no evidence of meningoencephalitis was observed in any animals that inhaled either 1 or $12 \mu \mathrm{m}$ particle inhalational infections. In the terminal stages of infection, bacteria were observed within the meningeal capillaries due to bacteraemic dissemination. This observation is similar to that of Zaucha et al. (1998), where much lower numbers of rabbits $(18 \%)$ presented with infection of the meninges, attributed to the rapidly fatal progression of the systemic infection limiting the opportunity for meningeal anthrax to develop. Furthermore, there was no involvement of the olfactory neurone, present in the nasal passages providing direct access to the brain. The olfactory neurone has recently been observed to be infected after the intranasal deposition of Burkholderia pseudomallei into the upper airways producing encephalitis (Owen et al., 2009).

\section{The rPA vaccine is protective against both small- and large-particle inhalational infections}

A subunit vaccine based on the rPA constituent of anthrax toxin has been developed. The rPA vaccine is efficacious against anthrax caused by the inhalation of endospores within a small-particle aerosol in murine and non-human primate models (Flick-Smith et al., 2005; Williamson et al., 2005). This study determined the efficacy of the rPA vaccine against the infection caused by the inhalation of $B$. anthracis endospores within large particles that deposit in the URT (Table 2). The mean total anti-rPA IgG concentration was determined pre-challenge as $3.04 \pm 1.52 \mu \mathrm{g} \mathrm{ml}^{-1}(n=30)$. Those mice that were challenged with $B$. anthracis endospores within 1 or $12 \mu \mathrm{m}$ particle aerosols displayed anti-rPA IgG concentrations of $4.80 \pm 2.99$ and $1.28 \pm 0.32 \mu \mathrm{g} \mathrm{ml}^{-1}$, respectively $(n=15)$. There was no significant difference between particle size groups $(P=0.26)$.

Mice were exposed to approximately 10 MLDs of $B$. anthracis endospores within either 1 or $12 \mu \mathrm{m}$ particle aerosols. Significant differences between the control and immunized mice were observed for the infections caused by the inhalation of $B$. anthracis within both 1 and $12 \mu \mathrm{m}$ particle aerosols $(P<0.05)$. All of the control mice that were immunized with diluent alone and challenged with a $1 \mu \mathrm{m}$ particle aerosol containing $B$. anthracis died, with a MTD of $100 \pm 8.89 \mathrm{~h}$. In contrast, only $87 \%$ of mice that were challenged with a $12 \mu \mathrm{m}$ particle aerosol containing $B$. anthracis died, with a MTD of $124.6 \pm 8.65$ h. However, particle size did not significantly alter survival of vaccinated mice $(P>0.05)$. Immunization resulted in $73 \%(11 / 15)$

Table 2. Protection of $A / J$ mice against aerosol exposure of $B$. anthracis $S T I$ endospores of different particle size after vaccination with $1 \mu \mathrm{g} r P A$

\begin{tabular}{|c|c|c|c|c|}
\hline Particle size $(\mu \mathrm{m})$ & Immunized & Mean anti-rPA titre $\left(\mu \mathrm{g} \mathrm{ml}^{-1}\right)$ & No. of survivors & Survival $(\%)^{\star}$ \\
\hline \multirow[t]{2}{*}{$1-3$} & - & $0.00 \pm 0.00$ & $0 / 15$ & 0 \\
\hline & + & $4.80 \pm 2.99$ & $11 / 15$ & 73 \\
\hline \multirow[t]{2}{*}{12} & - & $0.00 \pm 0.00$ & $2 / 15$ & 13 \\
\hline & + & $1.29 \pm 0.32$ & $12 / 15$ & 80 \\
\hline
\end{tabular}

${ }^{\star}$ Vaccinated mice with the lowest titres succumbed to infection. 
and $80 \%(12 / 15)$ survival when mice were challenged with 1 and $12 \mu \mathrm{m}$ particle aerosols, respectively. The fact that some immunized mice succumbed to infection was attributable to the immunization schedule employed with these animals exhibiting non-protective IgG titres ranging from undetectable levels to less than $0.1 \mu \mathrm{g} \mathrm{ml}^{-1}$ (data not shown). Clearance of $B$. anthracis within survivors was confirmed by bacteriological and histological analysis of spleen and lung tissues. No evidence of immunizationassociated pathology was observed in immunized mice.

Optimization of rPA formulations and immunization schedules by intranasal, intramuscular and oral delivery routes in $\mathrm{A} / \mathrm{J}$ mice has previously been undertaken, demonstrating efficacy against small-particle inhalational anthrax (Flick-Smith et al., 2002, 2005; Stokes et al., 2007). This study employed a suboptimal single-dose immunization schedule to enable differentiation between groups challenged with either small- or large-particle aerosols. Based on the results of Flick-Smith et al. (2002, 2005), implementation of a two-dose schedule or increased rPA dose would have increased the level of protection provided against inhalational challenge from $73-80 \%$ to closer to $100 \%$ by boosting antibody titres.

This study represents the first investigation of the effect of therapeutic intervention on respiratory anthrax infection caused by deposition of endospores within the URT. The data indicate that depending on the site of deposition the infection kinetics resulting from inhalational exposure to B. anthracis endospores may differ. However, the terminal point of an overwhelming bacteraemia is the same irrespective of whether the infection initiates in the LRT or URT; merely the site of initial dissemination into the bloodstream may differ. The small-particle inhalational infection presents as a necrotizing lymphadenitis of the SLNs with primary involvement of the lung lymphoid tissue. In contrast, the large-particle inhalational infection presents as a necrotizing lymphadenitis of the SLNs and mesenteric lymph nodes with primary gastritis in a number of cases. Indeed, human atypical presentations of inhalational anthrax have been observed with primary involvement of the nasopharyngeal or laropharyngeal regions of the respiratory tract. Symptoms such as rhinorrhoea, nasal congestion and epistaxis were more prevalent than in patients suffering from typical inhalational anthrax whilst the fatality rates were not statistically different (Holty et al., 2006a, b). A recent study simulating the bioterrorist attacks in the USA using Bacillus atrophaeus endospores demonstrated that particle sizes in the range of at least $1-9 \mu \mathrm{m}$ could be disseminated by opening a letter (Duncan \& Ho, 2008). Deposition after inhalation was generally within the lungs of swine; however, in some cases, considerable nasal deposition was observed (Duncan et al., 2009). Furthermore, clearance to the gastrointestinal tract or to local URT lymph nodes was not considered. The presence of different presentations of anthrax resulting from inhalational exposure requires consideration from the perspective of an intentional release and therapeutic intervention.

\section{ACKNOWLEDGEMENTS}

We recognize the contribution of Ministry of Defence funding for this work. Special thank you is reserved for personnel involved in animal husbandry related to the completion of the experiments at Dstl Porton Down, UK. We are grateful for the expertise of the scientific and technical staff at the Histopathology Department, VLA, Weybridge, UK, during the preparation and analysis of the histological samples.

\section{REFERENCES}

Beatty, M. E., Ashford, D. A., Griffin, P. M., Tauxe, R. V. \& Sobel, J. (2003). Gastrointestinal anthrax: review of the literature. Arch Intern Med 163, 2527-2531.

Butler, T., Fu, Y. S., Furman, L., Almeida, C. \& Almeida, A. (1982). Experimental Yersinia pestis infection in rodents after intragastric inoculation and ingestion of bacteria. Infect Immun 36, 1160-1167.

Cleret, A., Quesnel-Hellmann, A., Vallon-Eberhard, A., Vernier, B., Jung, S., Vidal, D., Mathieu, J. \& Tournier, J. N. (2007). Lung dendritic cells rapidly mediate anthrax spore entry through the pulmonary route. J Immunol 178, 7994-8001.

Day, W. C. \& Berendt, R. F. (1972). Experimental tularaemia in Macaca mulatta: relationship of aerosol particle size to the infectivity of airborne Pasteurella tularensis. Infect Immun 5, 77-82.

Druett, H. A., Henderson, D. W., Packman, L. P. \& Peacock, S. (1953). Studies on respiratory infection. I. The influence of particle size on respiratory infection with anthrax spores. J Hyg (Lond) 51, 359-371.

Druett, H. A., Robinson, J. M., Henderson, D. W., Packman, L. \& Peacock, S. (1956a). The influence of aerosol particle size on infection of the guinea-pig with Pasteurella pestis. J Hyg (Lond) 54, $37-48$.

Druett, H. A., Henderson, D. W. \& Peacock, S. (1956b). Studies on respiratory infection. III. Experiments with Brucella suis. J Hyg (Lond) 54, 49-57.

Drysdale, M., Heninger, S., Hutt, J., Chen, Y., Lyons, C. R. \& Koehler, T. M. (2005). Capsule synthesis by Bacillus anthracis is required for dissemination in murine inhalation anthrax. EMBO J 24, 221-227.

Duc, L. H., Hong, H. A., Fairweather, N., Ricca, E. \& Cutting, S. M. (2003a). Bacterial spores as vaccine vehicles. Infect Immun 71, 28102818.

Duc, L. H., Hong, H. A. \& Cutting, S. M. (2003b). Germination of the spore in the gastrointestinal tract provides a novel route for heterologous antigen delivery. Vaccine 21, 4215-4224.

Duncan, S. \& Ho, J. (2008). Estimation of viable spores in Bacillus atrophaeus (BG) particles of 1 to $9 \mu \mathrm{m}$ size range. Clean Soil Air Water 36, 584-592.

Duncan, E. J. S., Kournikakis, B., Ho, J. \& Hill, I. (2009). Pulmonary deposition of aerosolized Bacillus atrophaeus in a swine model due to exposure from a simulated anthrax letter incident. Inhal Toxicol 21, 141-152.

Dunne, P. J., Moran, B., Cummins, R. C. \& Mills, K. H. G. (2009). $\mathrm{CD}_{11 \mathrm{c}^{+}} \mathrm{CD} \mathrm{a}^{+}$dendritic cells promote protective immunity to respiratory infection with Bordetella pertussis. J Immunol 183, 400-410.

Flick-Smith, H. C., Eyles, J. E., Hebdon, R., Waters, E. L., Beedham, R. J., Stagg, T. J., Miller, J., Alpar, H. O., Baillie, L. W. \& Williamson, E. D. (2002). Mucosal or parenteral administration of microsphereassociated Bacillus anthracis protective antigen protects against anthrax infection in mice. Infect Immun 70, 2022-2028.

Flick-Smith, H. C., Waters, E. L., Walker, N. J., Miller, J., Stagg, A. J., Green, E. D. \& Williamson, E. D. (2005). Mouse model characterisation 
for anthrax vaccine development: comparison of one inbred and one outbred mouse strain. Microb Pathog 38, 33-40.

Frankel, A. E., Kuo, S. R., Dostal, D., Watson, L., Duesbery, N. S., Cheng, C. P., Cheng, H. J. \& Leppla, S. H. (2009). Pathophysiology of anthrax. Front Biosci 14, 4516-4524.

Fritz, D. L., Jaax, N. K., Lawrence, W. B., Davis, K. J., Pitt, M. L., Ezzell, J. W. \& Friedlander, A. M. (1995). Pathology of experimental inhalation anthrax in the rhesus monkey. Lab Invest 73, 691-702.

Fujimura, Y., Takeda, M., Ikai, H., Haruma, K., Akisada, T., Harada, T., Sakai, T. \& Ohuchi, M. (2004). The role of $M$ cells of human nasopharyngeal lymphoid tissue in influenza virus sampling. Virchows Arch 444, 36-42.

Glomski, I. J., Corre, J.-P., Mock, M. \& Goossens, P. L. (2007a). Nonencapsulated toxigenic Bacillus anthracis presents a specific growth and dissemination pattern in naïve and protective antigenimmune mice. Infect Immun 75, 4754-4761.

Glomski, I. J., Piris-Gimenez, A., Huerre, M., Mock, M. \& Goossens, P. L. (2007b). Primary involvement of pharynx and Peyer's patch in inhalational and intestinal anthrax. PLoS Pathog 3, e76.

Glomski, I. J., Dumetz, F., Jouvion, G., Huerre, M. R., Mock, M. \& Goossens, P. L. (2008). Inhaled non-capsulated Bacillus anthracis in A/J mice: nasopharynx and alveolar space as dual portals of entry, delayed dissemination, and specific organ targeting. Microbes Infect 10, 1398-1404.

Goossens, P. L. (2009). Animal models of human anthrax: the quest for the holy grail. Mol Aspects Med 30, 467-480.

Gueirard, P., Ave, P., Balazuc, A.-M., Thiberge, S., Huerre, M., Milon, G. \& Guiso, N. (2003). Bordetella bronchiseptica persists in the nasal cavities of mice and triggers early delivery of dendritic cells in the lymph nodes draining the lower and upper respiratory tract. Infect Immun 71, 4137-4143.

Guyton, A. C. (1947). Measurement of the respiratory volumes of laboratory animals. Am J Physiol 150, 70-77.

Heine, H. S., Bassett, J., Miller, L., Hartings, J. M., Ivins, B. E., Pitt, M. L., Fritz, D., Norris, S. L. \& Byrne, W. R. (2007). Determination of antibiotic efficacy against Bacillus anthracis in a mouse aerosol challenge model. Antimicrob Agents Chemother 51, 1373-1379.

Holty, J.-E. C., Bravat, D. M., Liu, H., Olshen, R. A., McDonald, K. M. \& Owens, D. K. (2006a). Systematic review: a century of inhalational anthrax cases from 1900 to 2005. Ann Intern Med 144, 270-280.

Holty, J.-E. C., Kim, R. Y. \& Bravata, D. M. (2006b). Anthrax: a systematic review of atypical presentations. Ann Emerg Med 48, 200-211.

Jahnsen, F. L., Gran, E., Haye, R. \& Brandtzaeg, P. (2004). Human nasal mucosa contains antigen-presenting cells of strikingly different functional phenotypes. Am J Respir Cell Mol Biol 30, 31-37.

Jernigan, D. B., Raghunathan, P. L., Bell, B. P., Brechner, R., Bresnitz, E. A., Butler, J. C., Cetron, M., Cohen, M., Doyle, T. \& other authors (2002). Investigation of bioterrorism-related anthrax, United States 2001: epidemiologic findings. Emerg Infect Dis 8, 1019-1028.

Kang, T. J., Basu, S., Zhang, L., Thomas, K. E., Vogel, S. N., Baillie, L. \& Cross, A. S. (2008). Bacillus anthracis spores and lethal toxin induce IL-1 $\beta$ via functionally distinct signalling pathways. Eur J Immunol 38, $1574-1584$.

Kang, T. J., Lee, G. S., Kim, S. K., Jin, S. H. \& Chae, G. T. (2010). Comparison of two mice strains, A/J and C57BL/6, in caspase-1 activity and IL- $1 \beta$ secretion of macrophage to Mycobacterium leprae infection. Mediators Inflamm (in press).

Kwa, S.-F., Beverley, P. \& Smith, A. L. (2006). Peyer's patches are required for the induction of rapid Th1 responses in the gut and mesenteric lymph nodes during an enteric infection. J Immunol 176, 7533-7541.
Lever, M. S., Stagg, A. J., Nelson, M., Pearce, P., Stevens, D. J., Scott, A. M., Simpson, A. J. H. \& Fulop, M. J. (2008). Experimental respiratory anthrax infection in the common marmoset (Callithrix jacchus). Int J Exp Pathol 89, 171-179.

Loving, C. L., Kennett, M., Lee, G. M., Grippe, V. K. \& Merkel, T. J. (2007). Murine aerosol challenge model of anthrax. Infect Immun $\mathbf{7 5}$, 2689-2698.

Loving, C. L., Khurana, T., Osorio, M., Lee, G. M., Kelly, V. K., Stibitz, S. \& Merkel, T. J. (2009). Role of anthrax toxins in dissemination, disease progression, and induction of protective adaptive immunity in the mouse aerosol challenge model. Infect Immun 77, 255-265.

Lyons, C. R., Lovchik, J., Hutt, J., Lipscomb, M. F., Wang, E., Heninger, S., Berliba, L. \& Garrison, K. (2004). Murine model of pulmonary anthrax: kinetics of dissemination, histopathology, and mouse strain susceptibility. Infect Immun 72, 4801-4809.

Macpherson, A. J. \& Smith, K. (2006). Mesenteric lymph nodes at the center of immune anatomy. J Exp Med 203, 497-500.

Meyer, M. A. (2003). Neurologic complications of anthrax. Arch Neurol 60, 483-488.

Nicholson, W. L., Farjado-Cavazos, P., Rebeil, R., Slieman, T. A., Reisenman, P. J., Law, J. F. \& Xue, Y. (2002). Bacterial endospores and their significance in stress resistance. Antonie van Leeuwenhoek 81, $27-32$.

Owen, S. J., Batzloff, M., Chehrehasa, F., Meedeniya, A., Casart, Y., Logue, C.-A., Hirst, R. G., Peak, I. R., Mackay-Sim, A. \& Beacham, I. R. (2009). Nasal-associated lymphoid tissue and olfactory epithelium as portals of entry for Burkholderia pseudomallei in murine melioidosis. J Infect Dis 199, 1761-1770.

Park, H.-S., Francis, K. P., Yu, J. \& Cleary, P. P. (2003). Membranous cells in nasal-associated lymphoid tissue: a portal of entry for the respiratory mucosal pathogen group A streptococcus. J Immunol 171, 2532-2537.

Passalacqua, K. D. \& Bergman, N. H. (2006). Bacillus anthracis: interactions with the host and establishment of inhalational anthrax. Future Microbiol 1, 397-415.

Redmond, C., Baillie, L. W. J., Hibbs, S., Moir, A. J. G. \& Moir, A. (2004). Identification of proteins in the exosporium of Bacillus anthracis. Microbiology 150, 355-363.

Reed, L. J. \& Muench, H. (1938). A simple method of estimating fifty per cent endpoints. Am J Hyg 27, 493-497.

Roy, C. J., Hale, M., Hartings, J. M., Pitt, L. \& Duniho, S. (2003). Impact of inhalation exposure modality and particle size on the respiratory deposition of ricin in Balb/c mice. Inhal Toxicol 15, 619-638.

Sanz, P., Teel, L. D., Alem, F., Carvalho, H. M., Darnell, S. C. \& O'Brien, A. D. (2008). Detection of Bacillus anthracis spore germination in vivo by bioluminescence imaging. Infect Immun 76, 1036-1047.

Setlow, P. (2006). Spores of Bacillus subtilis: their resistance to and killing by radiation, heat and chemicals. J Appl Microbiol 101, 514525.

Stokes, M. G. M., Titball, R. W., Neeson, B. N., Galen, J. E., Walker, N. J., Stagg, A. J., Jenner, D. C., Thwaite, J. E., Nataro, J. P. \& other authors (2007). Oral administration of a Salmonella enterica-based vaccine expressing Bacillus anthracis protective antigen confers protection against aerosolized B. anthracis. Infect Immun 75, 18271834.

Tam, M. A., Rydström, A., Sundquist, M. \& Wick, M. J. (2008). Early cellular responses to Salmonella infection: dendritic cells, monocytes, and more. Immunol Rev 225, 140-162.

Thomas, R. J., Webber, D., Sellors, W., Collinge, A., Frost, A., Stagg, A. J., Bailey, S. C., Jayasekera, P. N., Taylor, R. R. \& other authors 
(2008). Characterisation and deposition of respirable large and small particle bioaerosols. Appl Environ Microbiol 74, 6437-6443.

Thomas, R. J., Webber, D., Collinge, A., Stagg, A. J., Bailey, S. C., Nunez, A., Gates, A., Jayasekera, P. N., Taylor, R. R. \& other authors (2009). Different pathologies but equal levels of responsiveness to the recombinant $\mathrm{F} 1$ and $\mathrm{V}$ antigen vaccine and ciprofloxacin in a murine model of plague caused by small- and large-particle aerosols. Infect Immun 77, 1315-1323.

Todd, S. J., Moir, A. J. G., Johnson, M. J. \& Moir, A. (2003). Genes of Bacillus cereus and Bacillus anthracis encoding proteins of the exosporium. J Bacteriol 185, 3373-3378.

Tutrone, W. D., Scheinfeld, N. S. \& Weinberg, J. M. (2002). Cutaneous anthrax: a concise review. Cutis 69, 27-33.

Twenhafel, N. A., Leffel, E. \& Pitt, M. L. M. (2007). Pathology of inhalational anthrax infection in the African Green monkey. Vet Pathol 44, 716-721.

Van den Broeck, W., Derore, A. \& Simeons, P. (2006). Anatomy and nomenclature of murine lymph nodes: descriptive study and nomenclatory standardization in BALB/cAnNCrl mice. J Immunol Methods 312, 12-19.

Vasconcelos, D., Barnewall, R., Babin, M., Hunt, R., Estep, J., Nielsen, C., Carnes, R. \& Carney, J. (2003). Pathology of inhalation anthrax in cynomolgus monkeys (Macaca fascicularis). Lab Invest $\mathbf{8 3}$, 1201-1209.

Welkos, S. L., Keener, T. J. \& Gibbs, P. H. (1986). Differences in susceptibility of inbred mice to Bacillus anthracis. Infect Immun 51, 795-800.

Williamson, E. D., Hodgson, I., Walker, N. J., Topping, A. W., Duchars, M. G., Mott, J. M., Estep, J., LeButt, C., Flick-Smith, H. C. \& other authors (2005). Immunogenicity of recombinant protective antigen and efficacy against aerosol challenge with anthrax. Infect Immun $\mathbf{7 3}$, 5978-5987.

Zaucha, G. M., Pitt, L. M., Estep, J., Ivins, B. E. \& Friedlander, A. M. (1998). The pathology of experimental anthrax in rabbits exposed by inhalation and subcutaneous inoculation. Arch Pathol Lab Med 122, 982-992. 